\title{
AIAA 2000-3898
}

\section{Development Status of the NASA MC-1 (Fastrac) Engine}

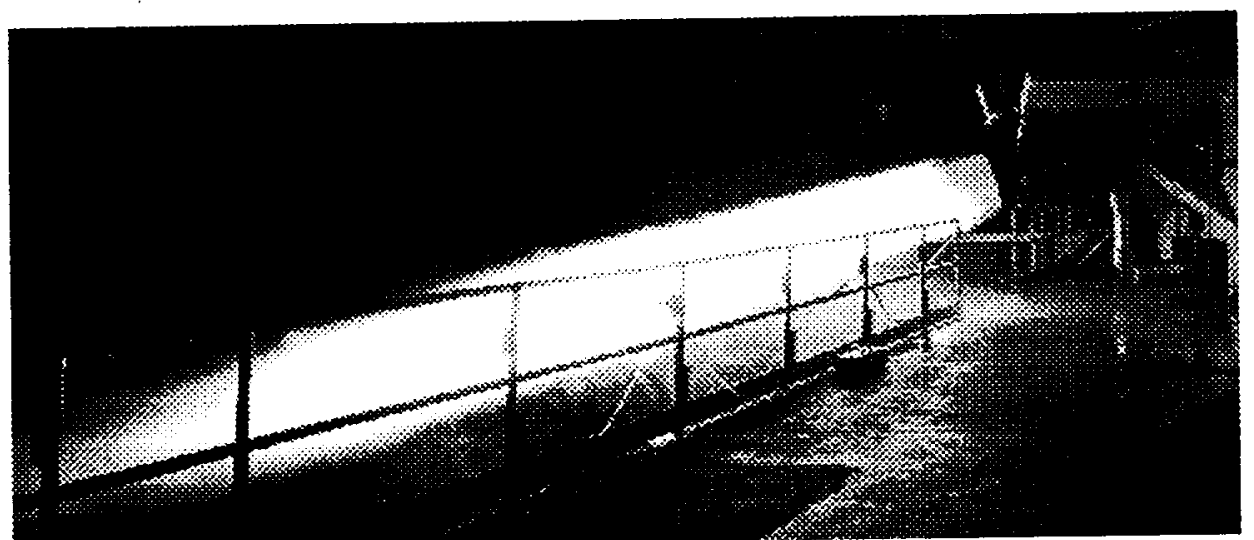

By

Richard O. Ballard

NASAMSFC

Tim Olive

NASAMSFC 


\section{Development Status of the NASA MC-1 (Fastrac) Engine}

\author{
By \\ Richard O. Ballard ${ }^{\dagger}$ \\ MC-1 Test \& Evaluation Team Lead \\ NASA/MSFC \\ Tim Olive \\ MC-1 Performance Analyst \\ NASA/MSFC
}

\section{Abstract}

The MC-1 (formerly known as the Fastrac $60 \mathrm{~K}$ ) Engine is being developed for the X-34 technology demonstrator vehicle. It is a pump-fed liquid rocket engine with fixed thrust operating at one rated power level of $60,000 \mathrm{lbf}$ vacuum thrust using a 15:1 area ratio nozzle (slightly higher for the 30:1 flight nozzle). Engine system development testing of the MC-1 has been ongoing since 24 Oct 1998 . To date. 48 tests have been conducted on three engines using three separate test stands. This paper will provide some details of the engine, the tests conducted, and the lessons learned to date.

\section{Introduction}

The MC-1 Engine is a pump-fed liquid rocket engine with fixed thrust and gimballing capability. The engine was initially designed for the Low Cost Boost Technology (LCBT) Project and for the X34 vehicle. The engine burns a mixture of RP-1 hydrocarbon fuel and liquid oxygen (LOX) propellants in a gas generator (GG) power cycle. Propellants are tapped from the engine propellant lines, and are burned as a fuel-rich mixture in a GG to power a turbine which rotates an in-line turbopump assembly. Both propellants pumps use a single-stage centrifugal impeller and the turbine is single-stage also. The fuel pump and main fuel injector use a dual-entry configuration to reduce flow velocity entering the component. Turbine exhaust gas is routed overboard via a turbine exhaust duct routed along side the engine nozzle. The chamber/nozzle is built as one piece with ablative liner and composite overwrap. The main injector uses 2-on-2 LOL impinging elements with fuel film cooling orifices drilled at the injector faceplate periphery. With the exception of the ablative thrust chamber, all components on the engine are reusable.

The engine uses a combination of electro-pneumatic and solenoid valves to control engine operation. The valves are designed to be either fully opened or fully closed. Helium is the working fluid in the pneumatic system. The two main propellant valves, the Main

AlAA Senior Member
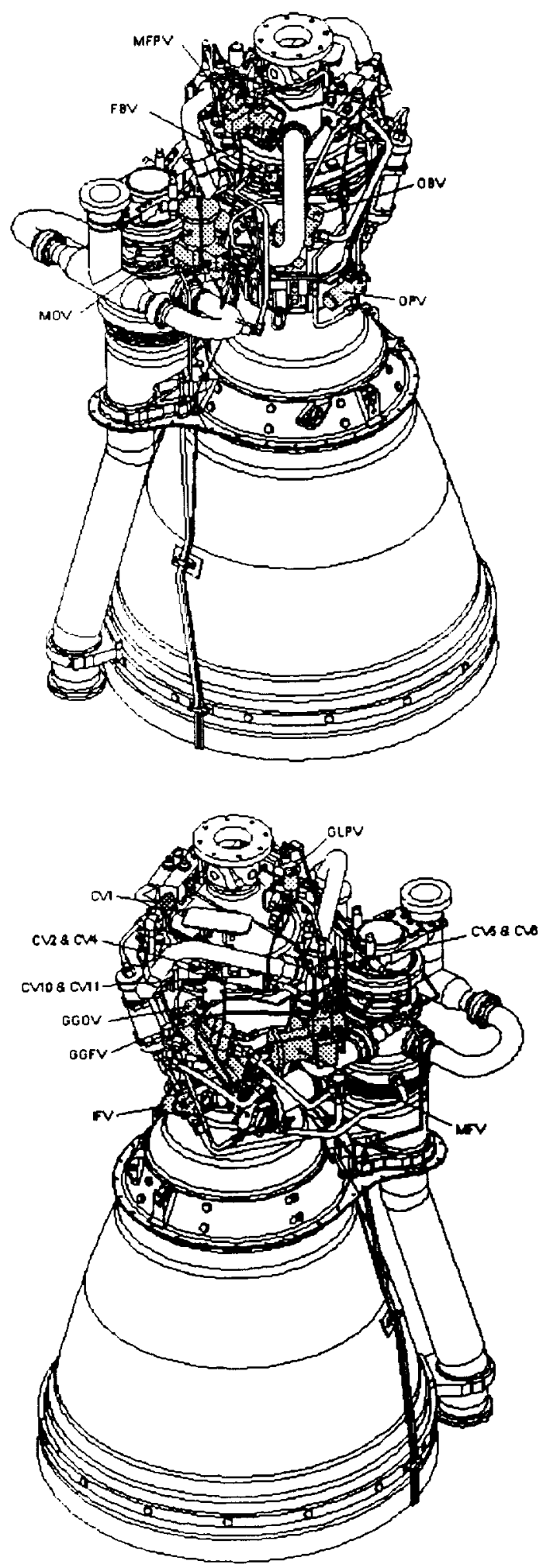

Figure 1: MC-1 Oblique Side Views 
Oxidizer Valve (MOV) and the Main Fuel Valve (MFV), are controlled by separate solenoid pilot valves. Four remaining electro-pneumatic valves. the Gas Generator Oxidizer Valve (GGOV). Gas Generator Fuel Valve (GGFV), Main Fuel Purge Valve (MFPV), and Oxidizer Bleed Valve (OBV) have built-in solenoid pilot valves. The remaining valves, the Ignitor Fue! Valve (IFV). Fuel Bleed Valve (FBV), Oxidizer Purge Valve (OPV), and Gas generator LOX Purge Valve (GLPV) are direct-acting solenoid valves. Seven check valves are also used to isolate the pneumatic system from the propellant systems. Figure I provides oblique views of the engine with the locations of most of the major components. Figure 2 shows a simplified schematic of the engine with the pneumatic, purge, and most vent/drain lines omitted.

The engine operates at one rated power level, nominally $60.000 \mathrm{lbf}$ at vacuum conditions for the $15: 1$ area ratio nozzle configuration, and slightly higher for the 30:1 nozzle. Thrust and mixture ratio are open loop controlled by setting tixed orifices in the engine propellant lines during engine calibration testing. Therefore, variations in engine propellant inlet conditions cause engine performance variations. Electrical commands for engine start and shutdown are issued by an electronic controller external to the engine.

The MC-I uses two ignition systems for engine start, one for the main chamber and one for the GG. Following spin-up of the turbopump from the vehicle/facility helium spin-start system, main chamber ignition is accomplished by injecting TEA/TEB hypergol from a piston-actuated reloadable cartridge. The IFV controls the timing for actuating the piston under fuel pressure. Ignition in the GG is performed by dual-mounted pyrotechnic squibs.

The engine is configurable for vertical operation. typical of booster application, or for horizontal application as used on the air-launched X-34 vehicle. The engine actuator attach ring includes mounting locations for thrust vector control actuators as required for the X-34 vehicle and Propulsion Test Article 1 (PTA 1 , test facility. The requirement for altitude start of the engine has made it necessary to simulate temperature conditions at launch altitude (approx. $38.060 \mathrm{ft}$.) in a "cold box" in order to cold soak the engine before ignition. This testing under a simulated launch environment has been very useful in identifying problem areas in the engine that have been corrected. Further development testing under simulated launch environments is planned.

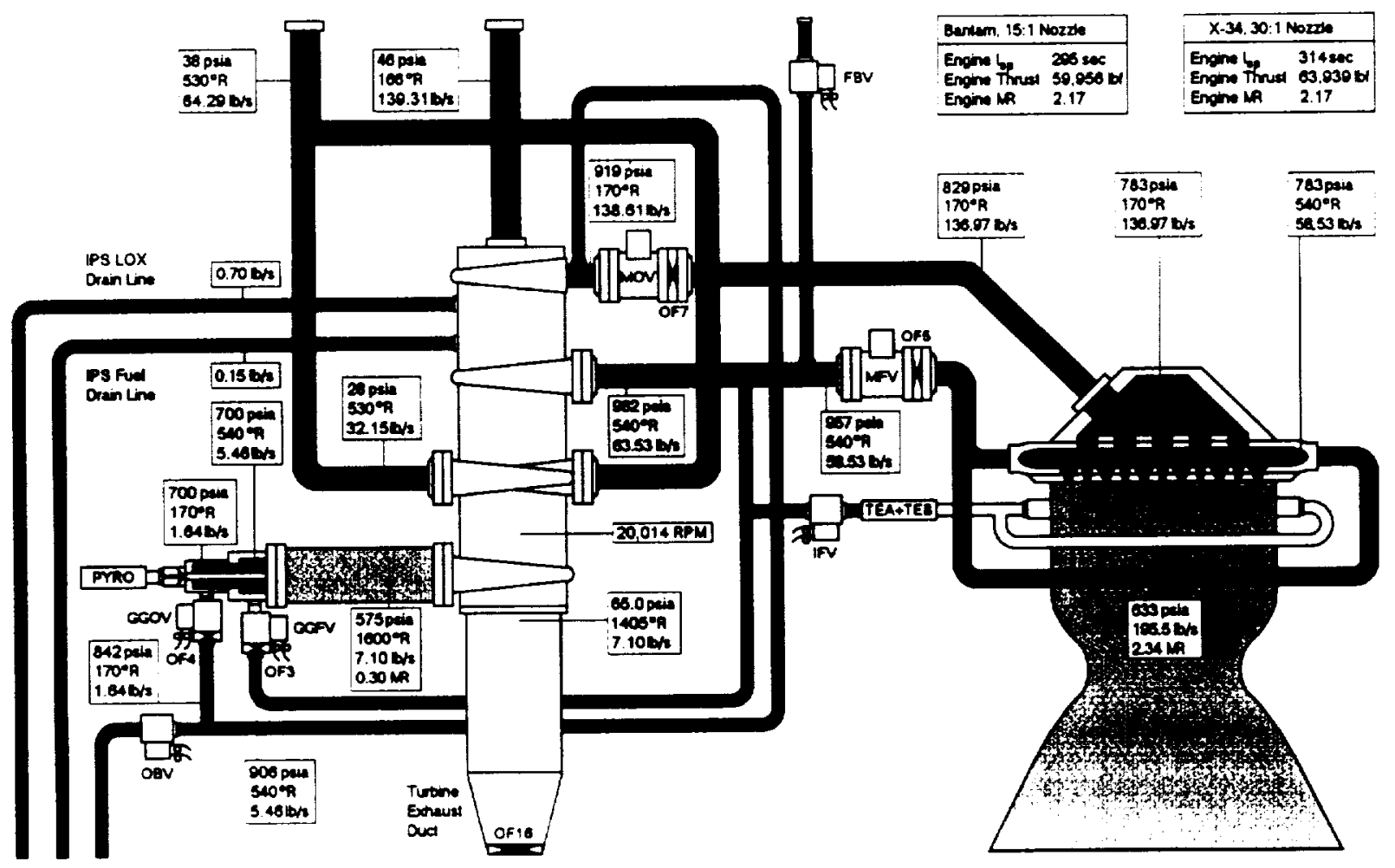

Figure 2: MC-I Engine Schematic (simplified) 


\section{Development Test Summary}

Engine system development testing of the MC-1 has been ongoing since 24 Oct 1998. To date, 48 tests have been conducted on three engines using three separate test stands: the Horizontal Test Facility (HTF) and the Propulsion Test Article-1 (PTA1) on the B2 test complex at Stennis Space Center (SSC), and the Alfa-l test stand at the Rocketdyne Santa Susannah Field Laboratory (SSFL). Of these tests, 33 were hot-fires with programmed durations ranging from 2.5 to 159 seconds, achieving a $58 \%$ rate of success fully operating for the full duration. Of the 14 premature cut-offs (PCO's), 10 were initiated by the engine with the remaining 4 caused by the test facility. Table 1 gives specific details of the engine tests conducted to date.

\begin{tabular}{|c|c|c|c|c|c|c|}
\hline $\begin{array}{c}\text { Test } \\
\text { H - HTF } \\
\text { P - PTAl } \\
\text { R - Alfal }\end{array}$ & Date & $\begin{array}{c}\operatorname{Time}(\mathrm{P} / \mathrm{A}) \\
(\operatorname{secs})\end{array}$ & Notes & 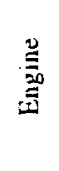 & $\frac{3}{\frac{3}{0}}$ & 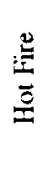 \\
\hline \multicolumn{7}{|c|}{ Ho Series - Engine/MPS Integrated Cold Flow Activation } \\
\hline $\mathrm{HO}-0$ & 24 Oct 98 & $-1 .$. & Dry countdown demo & $1^{*}$ & & \\
\hline $\mathrm{HO}-3$ & 28 Oct 98 & $--1 \cdots$ & Wet countdown demo & $1^{*}$ & $\mathrm{X}$ & \\
\hline $\mathrm{HO}-4$ & 09 Nov 98 & $2.0 / 2.0$ & GHe Spin Start Test & $1^{*}$ & $\mathrm{X}$ & \\
\hline $\mathrm{H} 0-4 \mathrm{R} 3$ & 09 Dec 98 & $2.0 / 2.0$ & GHe Spin Start Test (repeat) & $1 *$ & $\mathrm{X}$ & \\
\hline \multicolumn{7}{|c|}{\begin{tabular}{l|l} 
H0-4R3 & (9) Dec 98 \\
H1 Series - Start Sequence Definition \& Transition to Mainstage
\end{tabular}} \\
\hline $\mathrm{Hl}-\mathrm{I}$ & 11 Dec 98 & $2.5 / 2.52$ & Main Chamber Ignition Test (LOX only): OBV slow response & $1^{*}$ & & $\mathrm{X}$ \\
\hline H1-2 & $07 \operatorname{Jan} 99$ & $3.0 / 2.48$ & $\begin{array}{l}\text { Main Chamber lgnition Test (LOX/RP-1): PCO (ambient } \\
\text { powerhead temp by TEA/TEB leak); slow OBV }\end{array}$ & $1^{*}$ & & $\mathrm{X}$ \\
\hline $\mathrm{H} 1.3$ & $15 \operatorname{Jan} 99$ & $3.0 / 3.00$ & Main Chamber Ignition \& GG Fuel Prime Test : slow OBV & $1^{*}$ & & $\mathrm{X}$ \\
\hline $\mathrm{H} H-3 \mathrm{~S}$ & $22 \operatorname{Jan} 99$ & $-1-$ & $\begin{array}{l}\text { Special OBV/GGOV Cold-Flow Test ; slow OBV investigation; } \\
\text { data problems require repeat test }\end{array}$ & $1^{*}$ & $\mathrm{X}$ & \\
\hline $\mathrm{H} 1-3 \mathrm{SR}$ & $27 \operatorname{Jan} 99$ & .. $1 .$. & Special OBV/GGOV Cold-Flow Retest; slow OBV investigation & $1^{*}$ & $\mathrm{X}$ & \\
\hline H1-5 & 02 Feb 99 & $5.0 / 3.07$ & $\begin{array}{l}\text { Engine MINJ/GG Ignition \& Mainstage Test; PCO (GG Pc } \\
\text { ignition detect limit); slow OBV }\end{array}$ & $1^{*}$ & & $\mathrm{X}$ \\
\hline H1-5a & 06 Feb 99 & $5.0 / 3.44$ & $\begin{array}{l}\text { Engine MNJ/GG Ignition \& Mainstage Retest; abort (LOX VF } \\
\text { temp): PCO (GG Pc ignition detect); TEATTEB leak; slow OBV }\end{array}$ & $1 *$ & & $\mathrm{X}$ \\
\hline $\mathrm{HI}-2 \mathrm{a}$ & 19 Feb 99 & $3.0 / 2.76$ & $\begin{array}{l}\text { Engine MINJ Ignition Retest; PCO (Fuel LF pr lower limit); } \\
\text { slow OBV; TEA/TEB leak }\end{array}$ & $1^{*}$ & & $\mathrm{X}$ \\
\hline $\mathrm{HI}-4$ & 24 Feb 99 & $3.0 / 3.00$ & $\begin{array}{l}\text { MNJJ/GG Ignition Test; GOX leak past CV10; slow OBV; } \\
\text { TEA/TEB leak }\end{array}$ & $1 *$ & & $\mathbf{X}$ \\
\hline $\mathrm{H} 1-5 \mathrm{~b}$ & 02 Mar 99 & $5.0 / 5.00$ & $\begin{array}{l}\text { Engine MINJ/GG Ignition \& Mainstage Retest 2; MFV closure } \\
\text { failure: slow OBV; TEA/TEB leak }\end{array}$ & $1^{*}$ & & $\mathbf{X}$ \\
\hline $\mathrm{H} 1-6$ & 11 Mar 99 & $20.0 / 20.00$ & Mainstage Dwell Test; MFV ball seal displacement & $1 *$ & & $\mathrm{X}$ \\
\hline $\mathrm{H} 1-7$ & 15 Mar 99 & $-1-$ & MOV Cold-Flow Test (Rapid Engine Chill) & $1^{*}$ & $\mathbf{X}$ & \\
\hline \multicolumn{7}{|c|}{ H2a Series - Propellant Inlet Effects Gains Initial Baseline } \\
\hline $\mathrm{H} 2 \mathrm{a}-1$ & 24 Apr 99 & $12.0 / 12.01$ & Mainstage Dwell Test & $2 *$ & & $\mathrm{X}$ \\
\hline $\mathrm{H} 2 \mathrm{a}-2$ & 30 Apr 99 & $24.0 / 3.36$ & $\begin{array}{l}\text { Low Pressure Start \& Mainstage Test; PCO (GG Pc ignition } \\
\text { detect) }\end{array}$ & $2 *$ & & $\mathrm{X}$ \\
\hline $\mathrm{H} 2 \mathrm{a}-2 \mathrm{a}$ & 06 May 99 & $24.0 / 1.56$ & $\begin{array}{l}\text { Low Pressure Start \& Mainstage Test R1; PCO (SV9 GHe Spin } \\
\text { Start Valve deactivated) }\end{array}$ & $2 *$ & & $\bar{X}$ \\
\hline $\mathrm{H} 2 \mathrm{a}-2 \mathrm{~b}$ & 08 May 99 & $24.0 / 24.01$ & Low Pressure Start \& Mainstage Test R2 & $2 *$ & & $\mathrm{X}$ \\
\hline \multicolumn{7}{|c|}{$\mathrm{H} 2 \mathrm{~b}$ Series - Engine Orifice Gains Validation } \\
\hline $\mathrm{H} 2 \mathrm{~b}-\mathrm{l}$ & 11 May 99 & $24.0 / 24.01$ & GGOV Orifice Gains Test \#1 & $2 *$ & & $\mathbf{X}$ \\
\hline $\mathrm{H} 2 \mathrm{~b}-2$ & 14 May 99 & $159.0 / 159.03$ & GGFV Orifice Gains Test \#1 & $2^{*}$ & & $\mathbf{X}$ \\
\hline \multicolumn{7}{|c|}{ H3 Series - Engine Calibration \& Helium Consumption } \\
\hline $\mathrm{H} 3-1$ & 16 Aug 99 & $24.0 / 24.01$ & LOX Pump Inlet Variation Test & $1^{\bullet}$ & & $\bar{X}$ \\
\hline $\mathrm{H}^{3}-1 \mathrm{a}$ & 21 Aug 99 & $24.0 / 9.20$ & LOX Pump Inlet Variation Retest; PCO (network failure) & $1^{\bullet}$ & & $\mathrm{X}$ \\
\hline $\mathrm{H} 3-1 \mathrm{~b}$ & $10 \operatorname{Sep} 99$ & $24.0 / 24.02$ & LOX Pump Inlet Variation Retest \#2 & $1 \bullet$ & & $\mathrm{X}$ \\
\hline $\mathrm{H} 3-2$ & $14 \operatorname{Sep} 99$ & $24.0 / 3.05$ & $\begin{array}{l}\text { Baseline Inlet Conditions Test; PCO (GG Pc ignition detect } \\
\text { limit) }\end{array}$ & $1 \bullet$ & & $\mathrm{X}$ \\
\hline $\mathrm{H} 3-3$ & $18 \operatorname{Sep} 99$ & $24.0 / 3.13$ & Start Mod \#3; PCO (GG Pc ignition detect limit) & $1 \cdot$ & & $\mathrm{X}$ \\
\hline $\mathrm{H} 3-4$ & 21 Sep 99 & $159.0 / 3.12$ & Orifice Adjustment Test: PCO (GG Pc ignition detect limit) & $1 \cdot$ & & $\mathrm{X}$ \\
\hline $\mathrm{H} 3-5$ & $070 \mathrm{ct} 99$ & $24.0 / 24.01$ & Start Mod $\$ 5$ Test & $1 \cdot$ & & $\mathrm{X}$ \\
\hline $\mathrm{H} 3-6$ & 070 ct 99 & $24.0 / 24.01$ & Star Mod \#5 Verification / RP Ramp Test & $1^{\bullet}$ & & $\mathrm{X}$ \\
\hline
\end{tabular}




\begin{tabular}{|c|c|c|c|c|c|c|}
\hline \multicolumn{7}{|c|}{ H4 Series - Cold Engine Start Variations } \\
\hline $\mathrm{H} 4-1$ & 25 Oct 99 & $12.0 / 12.01$ & Baseline Ambient Start Test & $2^{\circ}$ & & $\mathbf{X}$ \\
\hline $\mathrm{H} 4-2$ & $280 \mathrm{Oct} 99$ & $12.0 / 11.16$ & $\begin{array}{l}\text { Cold Box / LOX \& RP Conditioning Test; PCO (IPS Ghe cavity } \\
\text { pr upper limit) }\end{array}$ & $2^{\bullet}$ & & $\mathbf{X}$ \\
\hline $\mathrm{H} 4-3$ & 29 Oct 99 & $12.0 / 12.01$ & $\begin{array}{l}\text { Cold Box / LOX \& RP Conditioning Test; TCA ignition event: } \\
\text { MLNJ damaged }\end{array}$ & $2^{\bullet}$ & & $\mathbf{X}$ \\
\hline H4-3S & 30 Oct 99 & $-.1-$ & $\begin{array}{l}\text { Investigation of H4-3 Anomaly Test; Cold Box thermal soak w/ } \\
\text { MFV cycling }\end{array}$ & $2 \bullet$ & $\bar{X}$ & \\
\hline $\mathrm{H} 4-4 \mathrm{a}$ & 11 Nov 99 & $--1-$ & Cold RP/LOX Drop Test: H4-3 investigation & $1 \cdot$ & $\mathbf{X}$ & \\
\hline $\mathrm{H} 4-4 \mathrm{~b}$ & 12 Nov 99 & $12.0 / 4.05$ & $\begin{array}{l}\text { Evaluation Hofire Test } \# 1 \text { for H4-3 Anomaly; PCO (slow OBV } \\
\& \text { MOV) }\end{array}$ & $1 \cdot$ & & $\mathrm{X}$ \\
\hline $\mathrm{H} 4-5 \mathrm{a}$ & 13 Nor 99 & $-1 \ldots$ & $\begin{array}{l}\text { Cold RP Drop / Cold Box Test: H4-3 investigation; PSC failure; } \\
\text { test ops at SSC concluded }\end{array}$ & $1 \cdot$ & $\mathrm{X}$ & \\
\hline \multicolumn{7}{|c|}{ P0 Series - Engine/MPS Integrated Cold Flow \& Tanking } \\
\hline $\mathrm{P} 0-1 / 2$ & 23 Jul 99 & $2.0 /$ aborted & $\begin{array}{l}\text { Engine MPS Integrated Cold Flow and GHe Spin Test; aborted } \\
\text { duning A-S start by GHe supply pr LL }\end{array}$ & $3^{*}$ & $\mathrm{X}$ & \\
\hline $\mathrm{P} 0-1 / 2 \mathrm{a}$ & $27 \mathrm{Jul} 99$ & $2.0 / 1.10$ & $\begin{array}{l}\text { Engine/MPS Integrated Cold Flow and GHe Spin Retest; PCO } \\
\text { (Facility control net failure) }\end{array}$ & $3 *$ & $\mathrm{X}$ & \\
\hline \multicolumn{7}{|c|}{ P1 Series - Start Sequence } \\
\hline P1-1 & 02 Aug 99 & $3.0 / 3.00$ & Main Injector Ignition Test & $3 *$ & & $\mathbf{X}$ \\
\hline \multicolumn{7}{|c|}{ P2 Series - Initial Calibration \& Duration } \\
\hline $\mathrm{P} 2-1$ & 29 Sep 99 & $8.0 / 8.01$ & Full Star Sequence / Mainstage Short Dwell Test & $3^{*}$ & & $\mathrm{X}$ \\
\hline $\mathrm{P} 2-2$ & 01 Oct 99 & $159.0 / 126.11$ & $\begin{array}{l}\text { PTAI Full Duration Test: PCO (False cut in RP-1 VF Pr lower } \\
\text { limit) }\end{array}$ & 3* & & $\bar{x}$ \\
\hline \multicolumn{7}{|c|}{ R0 Series - Engine/MPS Integrated Cold Flow Activation } \\
\hline R0-0 & 06 Mar 00 & $-1-1$ & Dry countdokn demo & 3* & & \\
\hline $\mathrm{R} 0-1$ & 18 May 00 & $--1 \ldots$ & Wet countdoun demo & 3* & $\mathrm{X}$ & \\
\hline R0-2 & $13 \mathrm{Jun} 00$ & $2.0 / 2.0$ & GHe Spin Start Test & $3^{*}$ & $\mathrm{X}$ & \\
\hline \multicolumn{7}{|c|}{ R1 Series - Engine Star Sequence } \\
\hline $\mathrm{R} 1-1$ & 22 Jun 00 & $3.0 / 3.00$ & Main Injector Ignition Test & $3^{*}$ & & $\mathrm{X}$ \\
\hline $\mathrm{R} 1-2$ & $7 \mathrm{Jul} 00$ & $5.0 / 3.12$ & Full Start Sequence Test; PCO (GG ignitor failure) & $3 *$ & & $\mathbf{X}$ \\
\hline $\mathrm{R} 1-2 \mathrm{a}$ & $12 \mathrm{Jul} 00$ & $5.01 / . .-$ & Full Stan Sequence Test Repeat & $3^{*}$ & & $\mathbf{X}$ \\
\hline
\end{tabular}

Table 1: MC-1 Development Tests

\section{Engine Performance Summary}

The MC- 1 engine uses fixed diameter orifices to calibrate the engine to thrust level, turbine inlet temperature, and engine mixture ratio. Table 2 provides a summary of key MC-1 Engine performance requirements.

\begin{tabular}{|l|c|c|}
\hline \multicolumn{1}{|c|}{ PARAMETER } & NOMINAL & RANGE \\
\hline Main Combustion Chamber Pressure, Pc $(\mathrm{psia})$ & 652.0 & $639.0-665.0$ \\
\hline Turbine Inlet Temperature $\left({ }^{\circ} \mathrm{R}\right)$ & 1600.0 & $1560.0-1640.0$ \\
\hline Mixture Ratio $(\mathrm{O} / \mathrm{F})$ & 2.17 & $2.14-2.20$ \\
\hline Vacuum Thrust $(\mathrm{lbf})$ & 63,939 & $60,000-69,000$ \\
\hline Specific Impulse, $\mathrm{I}_{\text {sp }}(\mathrm{sec})$ & 314.0 & 310.0 (minimum) \\
\hline
\end{tabular}

Table 2: MC-1 Engine Key Performance Requirements

Table 3 provides a summary of engine test results that have been normalized to the design point propellant inlet conditions. To date, no engine has been calibrated; the engines tested have run excessively fuel rich in both the main combustion chamber and gas generator. Accordingly, turbine inlet temperatures and engine mixture ratio have been below specification. A primary objective of the next series of engine system development tests will be to calibrate the engine. Orifice sizing to fully calibrate the engine has been confounded by propellant flow-rate measurement problems. The flow meters chosen for engine system testing (and X-34 vehicle operation) were of the differential pressure type and were specitically designed to produce low differential pressures. It has been theorized that a LOX pump rotating cavitation phenomena has induced hydraulic transients in the feed system. These 
transients propagate into large uncertainties in the differential pressure flow-rate measurement. Future testing will use turbine flow meters, which are less susceptible to hydraulic transients.

\begin{tabular}{|l|c|c|c|c|}
\hline Test & Engine & $\begin{array}{c}\text { MCC PC } \\
(\mathrm{psia})\end{array}$ & $\begin{array}{c}\text { Turbine Temp } \\
\left({ }^{\circ} \mathrm{R}\right)\end{array}$ & Mixture Ratio* \\
\hline $\mathrm{H} 1-6$ & 1 & 616 & 1491 & 1.83 \\
\hline $\mathrm{H} 2 \mathrm{a}-1$ & 2 & 608 & 1504 & 1.86 \\
\hline $\mathrm{H} 2 \mathrm{a}-2 \mathrm{~b}$ & 2 & 651 & 1575 & 1.92 \\
\hline $\mathrm{H} 2 \mathrm{~b}-1$ & 2 & 661 & 1590 & 1.89 \\
\hline $\mathrm{H} 2 \mathrm{~b}-2$ & 2 & 652 & 1561 & 1.86 \\
\hline $\mathrm{H} 3-1$ & $1 \mathrm{R} 1$ & 639 & 1500 & 1.93 \\
\hline $\mathrm{H} 3-\mathrm{la}$ & $1 \mathrm{R} 1$ & 658 & 1628 & 1.95 \\
\hline $\mathrm{H} 3-\mathrm{lb}$ & $1 \mathrm{R} 1$ & 645 & 1515 & 1.89 \\
\hline $\mathrm{H} 3-5$ & $1 \mathrm{R} 1$ & 646 & 1544 & 2.00 \\
\hline $\mathrm{H} 3-6$ & $1 \mathrm{R} 1$ & 646 & 1543 & 2.06 \\
\hline $\mathrm{P} 2-2$ & 3 & 640 & 1546 & 2.01 \\
\hline $\mathrm{H} 4-1$ & 2 & 634 & 1545 & 2.04 \\
\hline $\mathrm{H} 4-2$ & 2 & 638 & 1557 & 1.99 \\
\hline $\mathrm{H} 4-3$ & 2 & 619 & 1532 & 2.01 \\
\hline
\end{tabular}

Table 3: MC-1 Engine Test Hotfire Summary

Other performance challenges were addressed during engine system testing. Most of the challenges are typical of an engine development program and are listed below.

- Start sequence modifications were required to make the engine start process more robust.

- Additional film cooling of the GG was required after inspections showed discoloration of the GG chamber wall.

- GG igniter modifications were required to prevent extinguishing of the composite solid propellant plug.

System level issues have been discovered that will have impacts on propulsion system $/ \mathrm{X}-34$ vehicle integration. Test data indicates the ablative nozzle throat diameter decreases through time (possibly through carbon deposition). This decreasing throat diameter causes the engine system performance to drift and the engine never truly reaches a steady-state performance level. Test data also indicates large heat input into the GG LOX system (possibly from the mass of the valves and brackets). This heat input causes engine system performance to drift as the system seeks thermal stabilization. Resolution of both of these issues will require integrated vehicle systems analysis.

\section{Development Test Lessons Learned}

Results of MC-1 development testing will have impacts on propulsion system $/ \mathrm{X}-34$ vehicle integration. A primary objective of development testing of any rocket engine is to identify and correct problem areas. The MC- 1 has been rigorously tested under a variety of configurations and environments, including horizontal and vertical orientation, simulated thermal conditions at launch (i.e., Cold Box), and conditioned propellants. This test regimen has been successful in illuminating and correcting several engine issues, some of which are described below:

MFV Cycling Anomaly - During Firing Readiness Test (FRT) operations prior to test H0-4R, it was noted that the MFV cycled open without being commanded by the Propulsion System Controller (PSC). Testing was discontinued until it could be determined I) if the MFV had actually cycled; 2 ) how it had cycled without being commanded; 3 ) how to prevent this event from reoccurring in the future. This caused significant concern due to the possibility that the root cause might allow other valves (esp. MOV) to cycle without being commanded. It was verified that the MFV did cycle without any command being issued by the controller. It was fortunate that the event occurred during the FRT, when no propellants were in the system. A fault tree was developed and investigated, pointing to the possibility that the MFV pneumatic piston may have been actuated by pressure from the MFPV vent port through the RP-I drain lines and entering the pneumatic piston through the MFVS vent port. Because the drain lines are not 
instrumented, verification of this failure mode was not possible. Part of the investigation involved a series of FRTs to cause the event to occur again, but it did not.

On the possibility of the existence of a "sneak circuit" between the vents of the MFPV and MFVS, the drain lines were separated to eliminate it. Lines $96 \mathrm{M} 31270$ and $96 \mathrm{M} 31142$ were separated from the 96M31274 MFPV drain line, shown below in Figures 3 and 4. To date, this anomaly has not recurred.

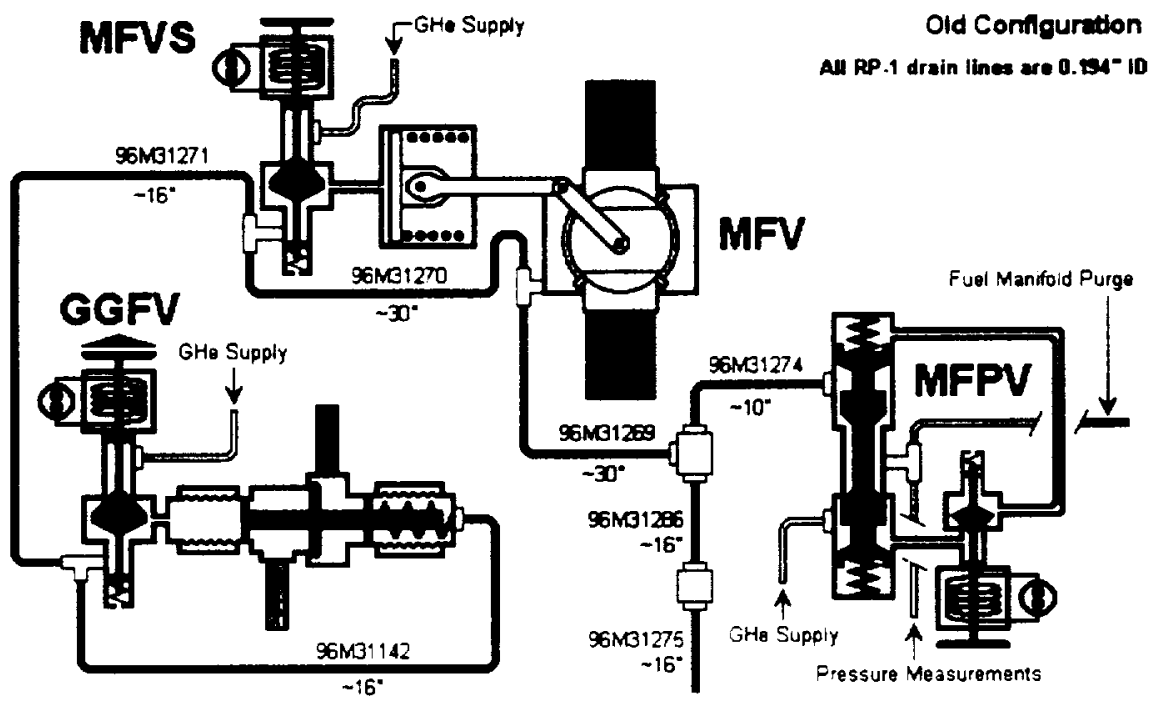

Figure 3: Old Vent Line Configuration

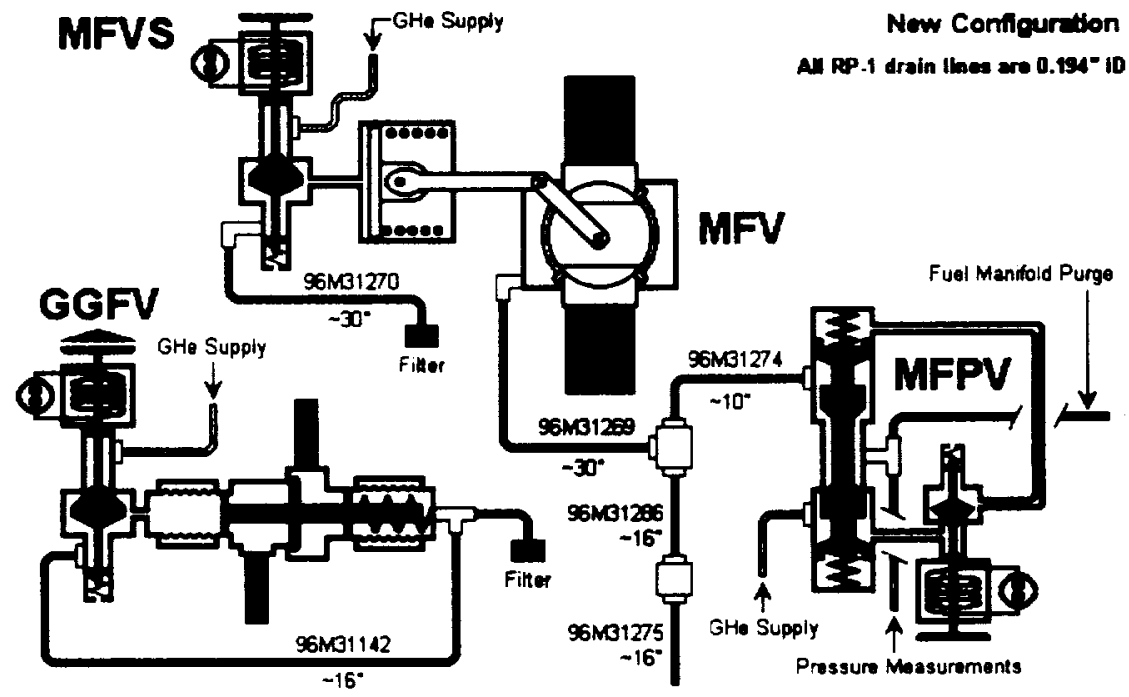

Figure 4: New Vent Line Configuration

Slow OBV Performance - The OBV is open during prestart operations to support engine chill and prevent LOX stagnation in the engine. It is supposed to close during start to prevent oxidizer starvation to the main chamber. Nominally, the OBV completes closure within 0.25 secs after the command is issued. However, it was noted in several tests that although the OBV would usually begin to close almost immediately after the close command was sent, it would take anywhere from several seconds to several minutes to complete closure. A fault tree was developed to investigate this anomaly and eventually a push pin in the pilot valve was removed that was suspected of being affected by cryogenic thermal loading. Removal of this pin resulted in improved valve performance. 
MFV Seal Failure - Immediately following shutdown on test $\mathrm{HI}-5 \mathrm{~b}$. some post-burning was noted in the main chamber for several seconds. The RP-1 afterburn stopped when the RP-1 facility prevalve closed as part of the normal facility shutdown. Review of the test data shorred that during shutdown the MFV left the OPEN switch but did not arrive at the CLOSED switch. This allowed fuel to enter the chamber after shutdown. The MFV was removed and inspected, which revealed the ball seal energizer springs extending into the flowpath (Figure 5), preventing the MFV from closing completely at shutdown. In addition. the ball had been scratched by the springs when it tried to close.

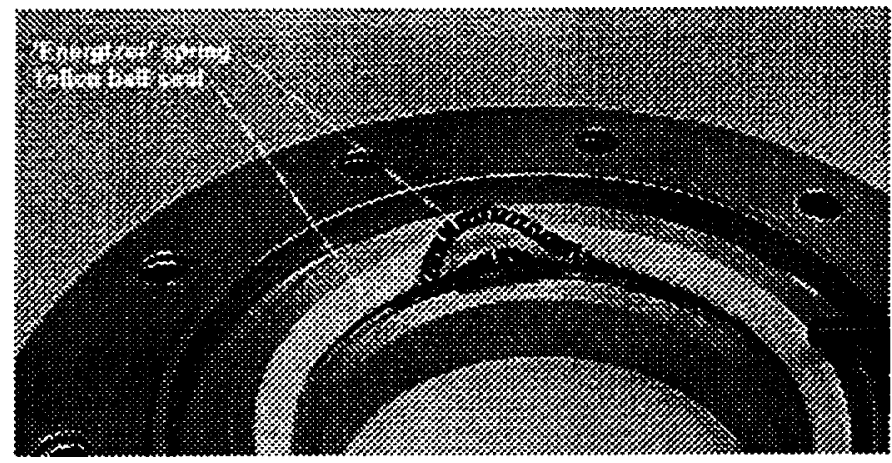

Figure 5: MFV Ball Seal Energizer Spring Extrusion

The MFV was shipped to the vendor for inspection and investigation. A serious concern with respect to this incident was that the MOV used a similar design and ball seal. and if it too failed. would cause a much more catastrophic event. Review of the seal design and water-flow tests revealed that the seal material was too flexible at ambient temperatures to maintain effective capture of the energizer springs. The heritage of the valve was adapted from an MOV design used on the RL10 engine and had been qualified for use under cryogenic temperatures when the material used in the seal is significantly stiffer. Because the GHe spin start pressure had been increased during the course of development testing to ensure adequate startup power to the turbopump, the pressure produced by the fuel pump at start had also increased, causing a high $\Delta \mathrm{p}$ across the valve when it initially opened. The reduced stiffness of the seal material degraded the ability of the seal to retain the energizer springs, which were extruded under the high $\Delta \mathrm{p}$ loading at start. As a corrective action. the ball seal design was modified to use a different material which had better stiffness at ambient temperatures.

GGFV Seal Failure - HTF test H3-la was terminated prematurely by a facility network failure. However, the GGFV did not close completely at engine shutdown. as evidenced by a post-shutdown fire which video shows to have been caused by flaming RP-1 exiting the turbine exhaust duct. The test data shows that during shutdown: 1) The GGFV leaves the open switch immediately following receipt of the CLOSE command but never arrives at the CLOSED switch;2) the GGFV discharge pressure does not decay immediately to ambient, which it normally does, but remains at $\sim 23$ psia until after $E / S+21$ and shows some behavior similar to that indicated in the fuel pump discharge pressure as a result of the waterhammer response from the MFV closure; 3 ) the turbine inlet temperature is significantly cooler than that shown in the previous test, possibly the result of a fuel-richer mixture ratio during shutdown.

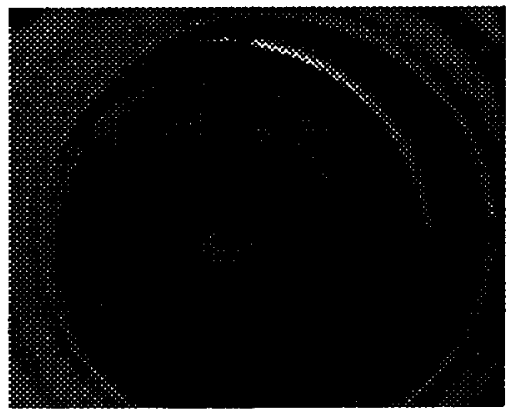

Figurc 6: GGFV Poppet Seal Spring Extrusion

Post-test inspection of the GGFV showed that poppet seal failure prevented the valve from closing (Figure 6). Because the GGFV is identical to the GGOV and OBV. there was concern over the possibility that the GGOV might fail to close at shutdown under similar circumstances. While a GGFV closure failure is relatively benign, a GGOV 
failure would be potentially catastrophic. An investigative team went from MSFC to the valve vendor to determine the cause of the seal failure and develop the remedial action. Water flow tests showed the seal design failed consistently at $\Delta \mathrm{p}$ `s of 100-200 psid under ambient conditions.

The primary cause of the GGFV seal failure was that the seal dimensional tolerances on the inner diameter did not adequately capture seal between the outlet plunger and inlet poppet. This allowed the seal lip on the inner diameter to jump over the retainer of the inlet poppet under high $\Delta \mathrm{p}$ conditions at either start or shutdown. A contributing cause was the inadequate material properties of the seal under ambient conditions did not provide sufficient stiffness to prevent deformation under $\Delta$ p loading at either start or shutdown. Corrective action to this anomaly was to redesign the seal to tighten dimensions and eliminate energizer spring. The redesign included reduction of the inner diameter and increase in the outer diameter. Elimination of the energizer spring and spring cavity resulted in a solid seal. The solid seal design should provide improved capture between the plunger and poppet, and increased seal stiffness. Water flow testing of the new seal showed significant improvement in $\Delta p$ range.

Start Sequence Modifications - One of the most critical phases of engine operation is start. During this time, valve sequencing is required to initiate the flow of propellants to the main chamber and GG, terminate oxidizer bleed flow, activate the helium spin start system, and operate the engine purges. The timing of these operations during engine start is crucial to ensure a safe engine start. The use of transient models is initially used to establish a preliminary start sequence, but actual engine hotfire testing is needed to anchor the models and fine-tune the start sequence. Redlines are established in several engine parameters to protect the engine during the start phase. A number of premature cut-offs experienced during engine testing occurred during the start phase and required some adjustments to valve sequence timing, helium spin start pressure, engine redlines, and the GG ignitor to increase the reliability and repeatability of the engine start operation. As a result, start performance has improved as the development test phase has progressed.

H4-3 Pop Anomaly - During hotfire testing to simulate the thermal environment at X-34 vehicle launch (i.e., "Cold Box"), the main chamber and injector of an MC-1 engine was damaged (Figure 7). This was revealed during posttest hardware inspections and engine data review, although the engine itself had operated for the full planned duration. A subsequent investigation suggested that the most probable cause of the event was the presence of residual fuel in the main chamber during engine start (Figure 8), which collected in the acoustic cavity following the previous test and detonated when LOX was introduced into the main chamber during the start sequence. It was also determined that this was not a flight issue, as the nozzle will be replaced after each flight, eliminating the risk associated with residual RP-1 accumulation in the acoustic cavity. Recurrence control included the establishment of requirements to inspect and remove residual fuel from the main chamber prior to hotfire testing.

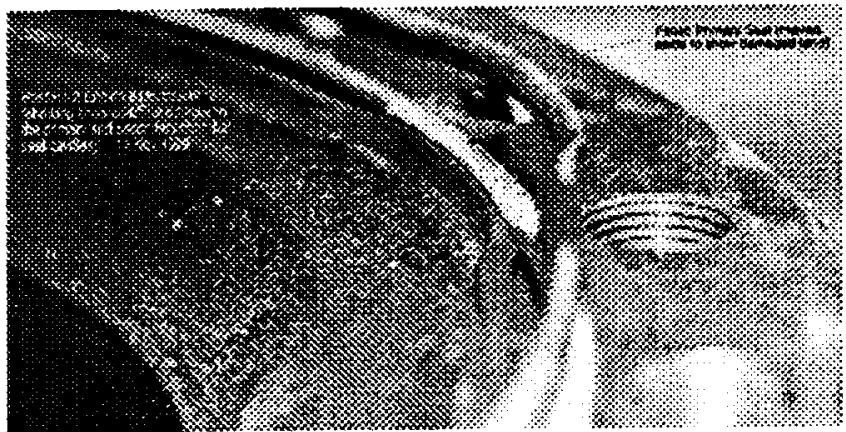

Figure 7: Damage to Chamber/MINJ Interface
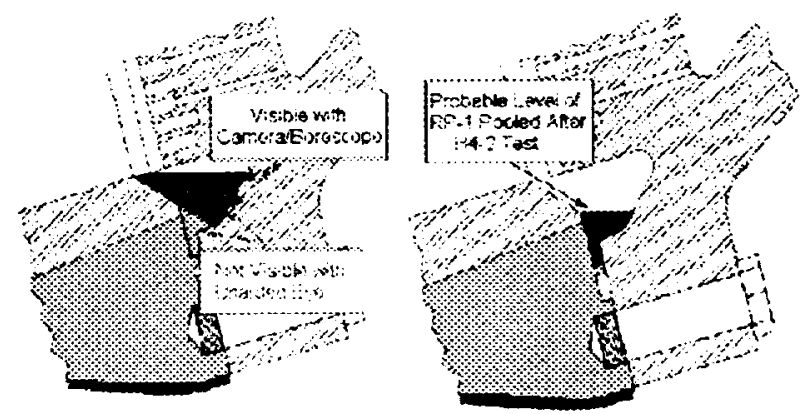

Figure 8: RP-1 Pooling in Acoustic Cavity

\section{Summary}

After a brief interruption in testing following the conclusion of testing at the HTF and PTAl test facilities at SSC, engine test operations have resumed at the Alfa-l test facility at the SSFL. Development testing is scheduled to be concluded in approximately nine months, followed by the Verification and Certification test phases. The MC-1 engine has shown itself to be a very robust design and no significant problems are anticipated that would prevent its being qualified for flight on the X-34 vehicle. 